Braz J Med Biol Res, February 2012, Volume 45(2) 158-162

doi: 10.1590/S0100-879X2012007500005

Vancomycin-resistant enterococcus outbreak in a pediatric intensive care unit: report of successful interventions for control and prevention

F. Carmona, S.I. Prado, M.F.I. Silva, G.G. Gaspar, F. Bellissimo-Rodrigues, R. Martinez, A.K. Matsuno and A.P.C.P. Carlotti

The Brazilian Journal of Medical and Biological Research is partially financed by

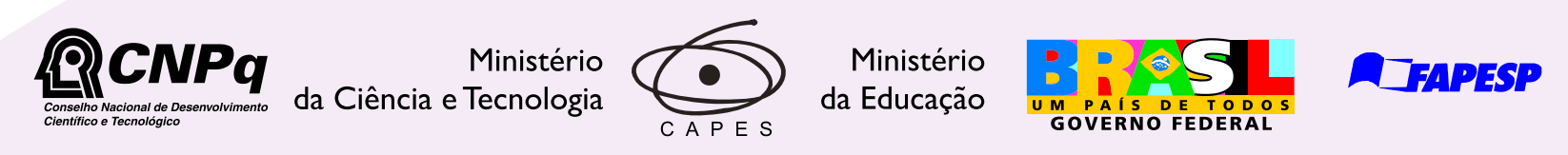

Institutional Sponsors
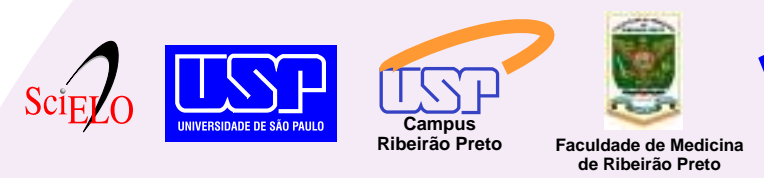

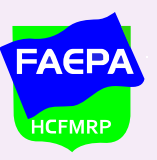

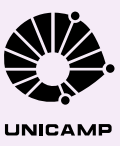

SHIMADZu

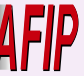

Associaçăo
Fundo de Incentivo
à Pesquisa

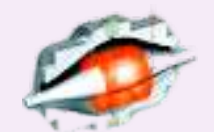

UNICAMP

lore High - Performance MS Orbitrap Technology analitica Thermo 


\title{
Vancomycin-resistant enterococcus outbreak in a pediatric intensive care unit: report of successful interventions for control and prevention
}

\author{
F. Carmona1 ${ }^{1}$, S.I. Prado², M.F.I. Silva², G.G. Gaspar², F. Bellissimo-Rodrigues ${ }^{3}$, \\ R. Martinez ${ }^{4}$, A.K. Matsuno ${ }^{1}$ and A.P.C.P. Carlotti ${ }^{1}$ \\ ${ }^{1}$ Centro de Terapia Intensiva Pediátrico, Departamento de Puericultura e Pediatria, Hospital das Clínicas, \\ Faculdade de Medicina de Ribeirão Preto, Universidade de São Paulo, Ribeirão Preto, SP, Brasil \\ ${ }^{2}$ Comissão de Controle de Infecção Hospitalar, Hospital das Clínicas, \\ Faculdade de Medicina de Ribeirão Preto, Universidade de São Paulo, Ribeirão Preto, SP, Brasil \\ ${ }^{3}$ Departamento de Medicina Social, Hospital das Clínicas, Faculdade de Medicina de Ribeirão Preto, \\ Universidade de São Paulo, Ribeirão Preto, SP, Brasil \\ ${ }^{4}$ Departamento de Clínica Médica, Hospital das Clínicas, Faculdade de Medicina de Ribeirão Preto, \\ Universidade de São Paulo, Ribeirão Preto, SP, Brasil
}

\begin{abstract}
The objective of this study is to retrospectively report the results of interventions for controlling a vancomycin-resistant enterococcus (VRE) outbreak in a tertiary-care pediatric intensive care unit (PICU) of a University Hospital. After identification of the outbreak, interventions were made at the following levels: patient care, microbiological surveillance, and medical and nursing staff training. Data were collected from computer-based databases and from the electronic prescription system. Vancomycin use progressively increased after March 2008, peaking in August 2009. Five cases of VRE infection were identified, with 3 deaths. After the interventions, we noted a significant reduction in vancomycin prescription and use ( $75 \%$ reduction), and the last case of VRE infection was identified 4 months later. The survivors remained colonized until hospital discharge. After interventions there was a transient increase in PICU length-of-stay and mortality. Since then, the use of vancomycin has remained relatively constant and strict, no other cases of VRE infection or colonization have been identified and length-of-stay and mortality returned to baseline. In conclusion, we showed that a bundle intervention aiming at a strict control of vancomycin use and full compliance with the Hospital Infection Control Practices Advisory Committee guidelines, along with contact precautions and hand-hygiene promotion, can be effective in reducing vancomycin use and the emergence and spread of vancomycin-resistant bacteria in a tertiary-care PICU.
\end{abstract}

Key words: Infections; Antibiotics misuse; Drug resistance; Vancomycin-resistant enterococcus

\section{Introduction}

Vancomycin overuse has been a concern for many years because of its role in selecting vancomycin-resistant enterococci (VRE) and vancomycin-resistant Staphylococcus aureus (VRSA) (1,2). In fact, correlations between antimicrobial consumption and resistance have already been demonstrated (3). VRE are usually resistant to other antimicrobials, are easily transmitted in the hospital setting and may transfer vancomycin resistance to other Grampositive organisms (4). In fact, VRSA has been already reported, carrying the enterococcal vanA gene complex, with altered cell wall composition and high resistance to both oxacillin and vancomycin (5).

In response to the increasing vancomycin misuse, in 1995, the United States Centers for Disease Control and Prevention - Hospital Infection Control Practices Advisory Committee (CDC-HICPAC) released the Recommendations for Preventing the Spread of Vancomycin Resistance, which contain instructions for prudent vancomycin use,

Correspondence: F. Carmona, Centro de Terapia Intensiva Pediátrico, Departamento de Puericultura e Pediatria, HC, FMRP, USP, Av. Bandeirantes, 3900, 14049-900 Ribeirão Preto, SP, Brasil. Fax: +55-16-3602-2700. E-mail: carmona@fmrp.usp.br

Received September 2, 2011. Accepted January 6, 2012. Available online January 27, 2012. Published February 17, 2012. 
role of microbiology laboratories in detection, reporting and control of VRE, as well as preventing and controlling nosocomial transmission of VRE (6). Since then, several groups have evaluated vancomycin use at their own institutions, and the reported prevalence of inappropriate use varied widely (20-100\%) in adults and children, primarily due to empirical therapy $(1,2,4,7-14)$. Recently, some of the HICPAC guidelines have been modified to reflect the need to empirically cover novel penicillin-resistant pneumococci and methicillin-resistant $S$. aureus (MRSA) (2).

Despite the HICPAC guidelines, multidrug-resistant bacterial infections have increased among Pediatric (PICU) and Neonatal (NICU) Intensive Care Units with impact on major outcomes such as mortality, length-of-stay and costs $(15,16)$.

In our institution, since 1998, the protocol for prophylaxis of bacterial infection in children undergoing open heart surgery has included vancomycin for those admitted 2 days or more before surgery, and vancomycin has been initiated against any suspected nosocomial infection in the postoperative period. Until recently, there were no guidelines about discontinuation of vancomycin use. In September 2008, the first VRE-colonized patient was identified in our hospital on the oncology ward. In August 2009, we identified the first (index) case of VRE infection in a pediatric patient in our institution, followed by 4 other cases, resulting in three deaths. This led to a series of meetings with the Infection Control Service (ICS) team, which resulted in the implementation of several practices to achieve full adherence to HICPAC guidelines. Therefore, the objective of this study was to report the results of these interventions in vancomycin use and VRE infections at our institution.

\section{Material and Methods}

\section{Study design}

This is a retrospective report on the results of systematic interventions in a PICU at Hospital das Clínicas, Faculdade de Medicina de Ribeirão Preto, Universidade de São Paulo (HC-FMRP-USP), a tertiary-care university hospital, carried out between August and September 2009. This unit assists patients undergoing major surgical procedures, mostly open heart surgery and neurosurgery, and patients from pediatric oncology wards with clinical or surgical complications.

\section{Vancomycin use before the interventions}

From 1998 to August 2009, our protocol for prophylaxis of bacterial infection in children undergoing open heart surgery was a) cephazolin ( $80 \mathrm{mg} / \mathrm{kg}$ loading dose plus $40 \mathrm{mg} / \mathrm{kg}$ every $8 \mathrm{~h}$ ) for patients admitted within $48 \mathrm{~h}$ before surgery, or b) vancomycin (10 mg/kg every $6 \mathrm{~h}$ ) plus amikacin $(7.5 \mathrm{mg} / \mathrm{kg}$ every $12 \mathrm{~h}$ ) for those admitted 2 days or more before surgery. These regimens were maintained for $48 \mathrm{~h}$ after surgery. In addition, when sternum closure was delayed, antibiotics were continued until $24 \mathrm{~h}$ after sternum closure. When a postoperative bacterial infection was suspected, vancomycin, plus a 3rd- or 4th-generation cephalosporin, were started and maintained for at least 7 days even when cultures resulted negative or identified a microorganism other than MRSA. Blood cultures were collected as single samples.

\section{Interventions}

After the identification of the first VRE infection, we started a series of meetings with the ICS staff to plan interventions at the following three levels: patient care, microbiological surveillance, and medical and nursing staff training. 1) Patient care: full compliance with the HICPAC guidelines for adequate use of vancomycin, bathing with a $2 \%$ chlorhexidine solution the night before surgery and on the day of surgery, changes in surgical prophylaxis (use of cephazolin for children admitted up to 5 days before surgery and those with negative routine screening cultures, MRSA decolonization with chlorhexidine bathing plus a nasal argentum sulfadiazine solution for 5 days for patients colonized with MRSA, adjustments of dose and timing of prophylactic antibiotics, maintenance of prophylaxis only for $24 \mathrm{~h}$ even in patients with an open chest, new loading doses right before chest closure), changes in treatment of postoperative infections (starting vancomycin only if deep surgical site- or central venous catheter-related infection or isolated MRSA or severe infections with sepsis was present and discontinuation if no MRSA was identified within the first $72 \mathrm{~h}$ ), collection of paired samples for blood cultures, geographic cohorting of patients with documented MRSA or VRE, and contact precautions and dedicated patient equipment. 2) Staff training: lectures on HICPAC guidelines, antibiotics stewardship, antisepsis for blood culture sample collection, emphasizing the importance of the antibiotic loading dose given immediately before the beginning of surgery, attention to extra doses of intraoperative antibiotics, careful hand degermation with $2 \%$ chlorhexidine at unit entry plus hand cleaning with gel alcohol, aseptic techniques for invasive procedures, routine environmental cleaning and disinfection, and avoiding hypothermia and hyperglycemia. 3) Microbiological surveillance: routine collection of surveillance cultures from patients transferred from other hospitals (blood, urine, tracheal, or nasal specimens, rectal swabs), routine collection of blood cultures and tracheal aspirates or nasal swabs from patients colonized with MRSA, and routine collection of blood cultures and rectal swabs from patients colonized with VRE.

\section{Data collection}

Data were collected from the ICS computer-based database and from the electronic prescription system, including: number of admissions, mean length-of-stay, mortality, prescriptions of vancomycin, dose of vancomycin used, and number and agents of infections, including VRE. The 
National Nosocomial Infections Surveillance (NNIS) system was used for nosocomial infection surveillance and report (17). VRE nosocomial infections were diagnosed according to CDC/NHSN criteria (18).

\section{Statistical analysis}

Data are reported as raw numbers and proportions, or as means \pm SD. There was no hypothesis test.

\section{Results}

In 2008, after the identification of the first VRE-colonized patient (rectal swab), VRE was isolated from 14 other patients (one from the surgical site and 13 from rectal swabs), and 12 were considered infected. All these patients were adults, and VRE was never found in pediatric patients until August 2009. In 2009, VRE was isolated from 29 adult plus 5 pediatric patients at many hospital sites, and 24 were considered infected. Only vancomycin-resistant Enterococcus faecium (VREfm) was isolated from all patients using automated methods with manual confirmation.

Since 1998, our unit has admitted 3065 patients (mean of 236 patients per year) or 2230 patients-day per year (mean of the last 4 years), with an incidence density of nosocomial infection of 23 episodes/patient-day and overall mortality rate of $11.8 \%$ (both in 2009). The use of vancomycin was about $200 \mathrm{mg} /$ patientsday during 2007, and in March 2008 we noted a progressive increase in vancomycin use, peaking in July 2008 and August 2009 (Figure 1). At that time, the first case of VRE infection was identified, followed by 4 other cases (Table 1 ), which resulted in 3 deaths (1 infected and 2 colonized). In all cases, only VREfm was isolated. VRE was not isolated from any other pediatric unit within our hospital.

Upon identification of the first case, the interventions were made. We then noted a significant $75 \%$ reduction in vancomycin prescription and use and 4 months later the last case of VREfm infection was identified. The survivors remained colonized until hospital discharge.

After the interventions, we noticed a transient increase in PICU length-of-stay and mortality (Figure 1). Since then, the use of vancomycin has remained relatively constant and strict, and despite the identification of 44 new cases of VRE-infected or colonized patients in our hospital, no other cases of VRE infection or colonization have been identified in our unit, and length-of-stay and mortality have returned to baseline.

\section{Discussion}

We have shown a significant reduction of vancomycin prescription and use and the control of vancomycin-resistant enterococcus spread in a Brazilian tertiary PICU after implementation of strict policies for vancomycin use and full compliance with HICPAC guidelines.

Decreasing the risk of infections with multidrug-resistant organisms by reducing overuse and misuse of antimicrobials is a major challenge to clinicians (1). Vancomycin misuse creates a selective pressure for the emergence of resistant bacteria, as we experienced. The proportion on VREfm increased over 10 years around the world,

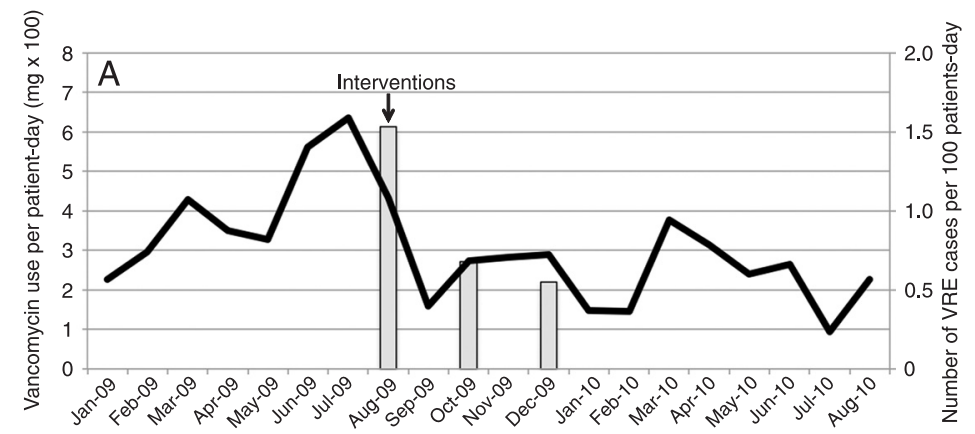

$\square$ Number of VRE cases per 100 patients-day —Vancomycin use per patient-day (mg x 100)
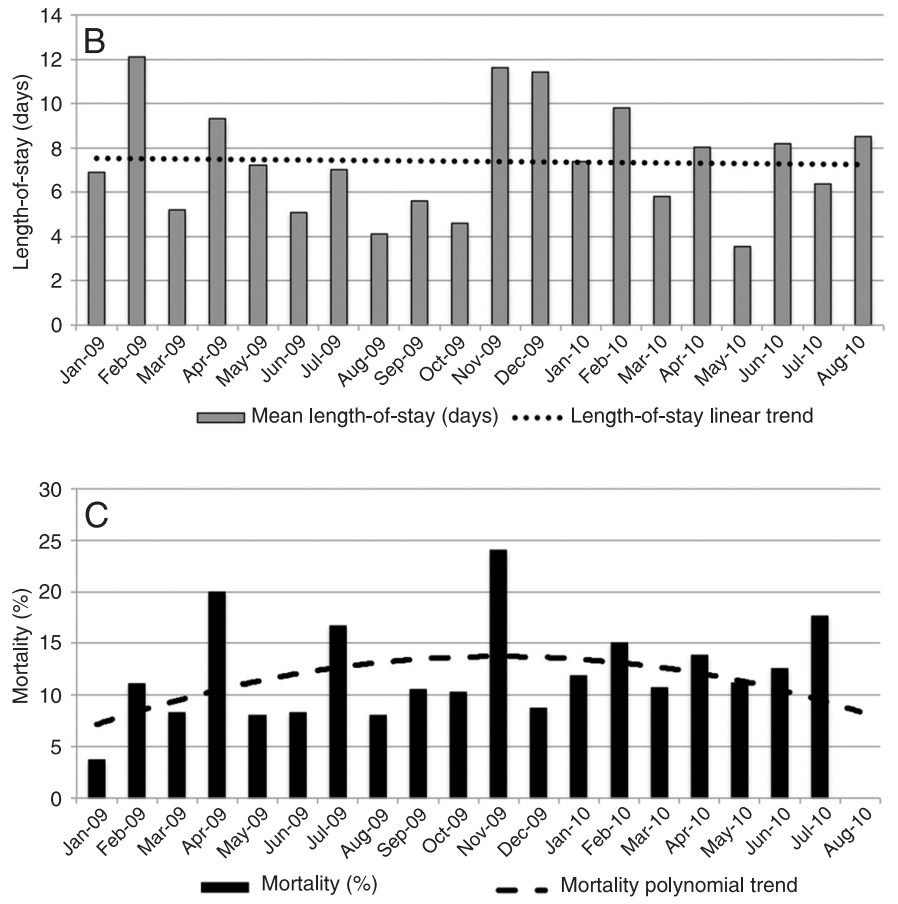

Figure 1. $A$, Vancomycin use per patient-day ( $\mathrm{mg} \times 100)$, number of vancomycin-resistant enterococci (VRE) cases per 100 patients-day; $B$, mean length-of-stay (with linear trend), and $C$, mortality (with polynomial trend) from January 2009 to August 2010. 
Table 1. Main characteristics of patients infected or colonized with vancomycin-resistant enterococci.

\begin{tabular}{|c|c|c|c|c|c|c|c|c|}
\hline Patient & Gender & $\begin{array}{c}\text { Age } \\
\text { (months) }\end{array}$ & Diagnosis & $\begin{array}{l}\text { Vancomycin } \\
\text { use }\end{array}$ & $\begin{array}{l}\text { Date of VREfm } \\
\text { identification }\end{array}$ & $\begin{array}{c}\text { Site of } \\
\text { identification }\end{array}$ & Outcome & $\begin{array}{l}\text { Hospital } \\
\text { length-of-stay }\end{array}$ \\
\hline 1 & Female & 8.9 & $\begin{array}{l}\text { Down syndrome, tetralogy } \\
\text { of Fallot (operated) }\end{array}$ & 49 days & 08-10-2009 & $\begin{array}{l}\text { Mediastinum } \\
\text { (infection) }\end{array}$ & Discharge & 127 days \\
\hline 2 & Female & 6.5 & $\begin{array}{l}\text { Down syndrome, atrial } \\
\text { septal defect plus patent } \\
\text { ductus arteriosus (both } \\
\text { operated) }\end{array}$ & 20 days & 08-14-2009 & $\begin{array}{l}\text { Blood stream } \\
\text { (infection) }\end{array}$ & Discharge & 41 days \\
\hline 3 & Male & 3.1 & $\begin{array}{l}\text { Situs inversus totalis, } \\
\text { biliary atresia, congenital } \\
\text { complete atrioventricular } \\
\text { block, complex heart } \\
\text { malformations (palliated) }\end{array}$ & 19 days & 08-28-2009 & $\begin{array}{l}\text { Rectal swab } \\
\text { (colonization) }\end{array}$ & Death & 154 days \\
\hline 4 & Male & 5 & $\begin{array}{l}\text { Bell's paralysis, total } \\
\text { atrioventricular septal } \\
\text { defect (operated), } \\
\text { vesicoureteral reflux }\end{array}$ & 1 day & 10-19-2009 & $\begin{array}{l}\text { Rectal swab } \\
\text { (colonization) }\end{array}$ & Death & 41 days \\
\hline 5 & Female & 2 & $\begin{array}{l}\text { Ventricular septal defect, } \\
\text { atrial septal defect, patent } \\
\text { ductus arteriosus, deep } \\
\text { vein thrombosis, renal } \\
\text { failure requiring peritoneal } \\
\text { dialysis }\end{array}$ & 3 days & 12-07-2009 & $\begin{array}{l}\text { Peritoneal } \\
\text { fluid (infection) }\end{array}$ & Death & 27 days \\
\hline
\end{tabular}

VREfm = vancomycin-resistant Enterococcus faecium.

whereas vancomycin-resistant $E$. faecalis (VREfc) remained constant. In Brazil, VREfc predominated until 1999, when dissemination of VREfm increased (19). Only VREfm was present in our patients.

Efforts should be directed at medical education on HICPAC guidelines and institutional policies for strict vancomycin use in order to control the emergence of resistant bacteria, as well as to reduce patient morbidity and mortality and healthcare costs $(1,9)$. In the presence of a VRE outbreak, recommendations include testing enterococcal isolates for vancomycin resistance, fecal screening to detect patients colonized with VRE and intensifying control programs and staff education (20). Reports on measures for the control of vancomycin use in a tertiary-care hospital, including lectures to medical staff, dissemination of HICPAC guidelines and computer-based automatic stop vancomycin order after $72 \mathrm{~h}$ and electronic alerts, have shown a $22 \%$ reduction in vancomycin prescriptions, but most prescriptions were still inappropriate according to HICPAC guidelines (21). After the interventions, we showed a $75 \%$ reduction in vancomycin use in our unit.

Several other reports have been published on successful efforts to control outbreaks of VRE in many settings, including general wards, hematology units, and general, neurosurgical and neonatal intensive care units $(16,19,22-27)$.
These interventions included creation of VRE control teams, cohorting of VRE carriers, active surveillance cultures for VRE, environmental cultures and cleaning, reinforcement of hand hygiene, and antibiotic control policies and education for the entire hospital staff $(15,19,22,24,25,27)$. One report of lack of effectiveness of such interventions in VRE control has associated it to the emergence of the ST203 E. faecium clone with the acquired vanB locus (26).

The present report has some limitations. First, we did not evaluate the effects of interventions on morbidity or costs of hospitalization. Second, in addition to close monitoring of vancomycin use, rates of compliance with VRE isolation precautions and hand washing were not actively and systematically assessed.

In conclusion, we showed that a bundle intervention aiming at the strict control of vancomycin use and full compliance with the HICPAC guidelines, along with contact precautions and hand-hygiene promotion can be effective in reducing vancomycin use and the emergence and spread of vancomycin-resistant bacteria in a tertiary-care PICU.

\section{Acknowledgments}

We thank Dr. Letícia de Melo for her invaluable medical contribution during the VRE outbreak. 


\section{References}

1. Hopkins HA, Sinkowitz-Cochran RL, Rudin BA, Keyserling $\mathrm{HL}$, Jarvis WR. Vancomycin use in pediatric hematologyoncology patients. Infect Control Hosp Epidemiol 2000; 21: 48-50.

2. Bolon MK, Arnold AD, Feldman HA, Rehkopf DH, Strong EF, Goldmann DA, et al. Evaluating vancomycin use at a pediatric hospital: new approaches and insights. Infect Control Hosp Epidemiol 2005; 26: 47-55.

3. Lai CC, Wang CY, Chu CC, Tan CK, Lu CL, Lee YL, et al. Correlation between antimicrobial consumption and resistance among Staphylococcus aureus and enterococci causing healthcare-associated infections at a university hospital in Taiwan from 2000 to 2009. Eur J Clin Microbiol Infect Dis 2011; 30: 265-271.

4. Shah SS, Sinkowitz-Cochran RL, Keyserling HL, Jarvis WR. Vancomycin use in pediatric neurosurgery patients. $A m \mathrm{~J}$ Infect Control 1999; 27: 482-487.

5. Severin A, Tabei K, Tenover F, Chung M, Clarke N, Tomasz A. High level oxacillin and vancomycin resistance and altered cell wall composition in Staphylococcus aureus carrying the staphylococcal mecA and the enterococcal vanA gene complex. J Biol Chem 2004; 279: 3398-3407.

6. Centers for Disease Control and Prevention (CDC). Recommendations for preventing the spread of vancomycin resistance: Recommendations of the Hospital Infection Control Practices Advisory Committee (HICPAC). Atlanta: Department of Health and Human Services; 1995.

7. Roghmann MC, Perdue BE, Polish L. Vancomycin use in a hospital with vancomycin restriction. Infect Control Hosp Epidemiol 1999; 20: 60-63.

8. Drinkovic D, Taylor SL, Pottumarthy S, Morris AJ. Prospective vancomycin audit in Auckland healthcare hospitals. $N Z$ Med J 1999; 112: 336-339.

9. Logsdon BA, Lee KR, Luedtke G, Barrett FF. Evaluation of vancomycin use in a pediatric teaching hospital based on CDC criteria. Infect Control Hosp Epidemiol 1997; 18: 780782.

10. Evans ME, Kortas KJ. Vancomycin use in a university medical center: comparison with hospital infection control practices advisory committee guidelines. Infect Control Hosp Epidemiol 1996; 17: 356-359.

11. Watanakunakorn C. Prescribing pattern of vancomycin in a community teaching hospital with low prevalence of vancomycin-resistant enterococci. Infect Control Hosp Epidemiol 1997; 18: 767-769

12. Cieslak PR, Strausbaugh LJ, Fleming DW, Ling JM. Vancomycin in Oregon: who's using it and why. Infect Control Hosp Epidemiol 1999; 20: 557-560.

13. Green K, Schulman G, Haas DW, Schaffner W, D'Agata EM. Vancomycin prescribing practices in hospitalized chronic hemodialysis patients. Am J Kidney Dis 2000; 35: 64-68.

14. Johnson SV, Hoey LL, Vance-Bryan K. Inappropriate vancomycin prescribing based on criteria from the Centers for Disease Control and Prevention. Pharmacotherapy 1995; 15: $579-585$
15. McGrath EJ, Asmar BI. Nosocomial infections and multidrugresistant bacterial organisms in the pediatric intensive care unit. Indian J Pediatr 2011; 78: 176-184.

16. Choudhry O, Gathwala G, Singh J. Vancomycin resistant Enterococci in neonatal ICU - a rising menace. Indian $J$ Pediatr 2010; 77: 1446-1447.

17. Emori TG, Culver DH, Horan TC, Jarvis WR, White JW, Olson DR, et al. National nosocomial infections surveillance system (NNIS): description of surveillance methods. Am J Infect Control 1991; 19: 19-35.

18. Horan TC, Andrus M, Dudeck MA. CDC/NHSN surveillance definition of health care-associated infection and criteria for specific types of infections in the acute care setting. $A m \mathrm{~J}$ Infect Control 2008; 36: 309-332.

19. Pereira GH, Muller PR, Zanella RC, de Jesus Castro Lima M, Torchio DS, Levin AS. Outbreak of vancomycin-resistant enterococci in a tertiary hospital: the lack of effect of measures directed mainly by surveillance cultures and differences in response between Enterococcus faecium and Enterococcus faecalis. Am J Infect Control 2010; 38: 406-409.

20. Brossier F, Lefrancois S, Paute J, Gouot A, Golmard JL, Chaibi $P$, et al. Decolonisation for early control of an outbreak of vancomycin-resistant Enterococcus faecium in a geriatric rehabilitation care facility. J Hosp Infect 2010; 76: 368-369.

21. Singer MV, Haft R, Barlam T, Aronson M, Shafer A, Sands $\mathrm{KE}$. Vancomycin control measures at a tertiary-care hospital: impact of interventions on volume and patterns of use. Infect Control Hosp Epidemiol 1998; 19: 248-253.

22. Yoon YK, Sim HS, Kim JY, Park DW, Sohn JW, Roh KH, et al. Epidemiology and control of an outbreak of vancomycinresistant enterococci in the intensive care units. Yonsei Med J 2009; 50: 637-643.

23. Moretti ML, de Oliveira Cardoso LG, Levy CE, Von Nowakosky A, Bachur LF, Bratfich O, et al. Controlling a vancomycin-resistant enterococci outbreak in a Brazilian teaching hospital. Eur J Clin Microbiol Infect Dis 2011; 30: 369-374.

24. Ergaz Z, Arad I, Bar-Oz B, Peleg O, Benenson S, Minster N, et al. Elimination of vancomycin-resistant enterococci from a neonatal intensive care unit following an outbreak. $J$ Hosp Infect 2010; 74: 370-376.

25. Ozorowski T, Kawalec M, Zaleska M, Konopka L, Hryniewicz $W$. The effect of an antibiotic policy on the control of vancomycin-resistant enterococci outbreak and on the resistance patterns of bacteria isolated from the blood of patients in a hematology unit. Pol Arch Med Wewn 2009; 119: 712-718.

26. Johnson PD, Ballard SA, Grabsch EA, Stinear TP, Seemann T, Young HL, et al. A sustained hospital outbreak of vancomycin-resistant Enterococcus faecium bacteremia due to emergence of vanB E. faecium sequence type 203. $J$ Infect Dis 2010; 202: 1278-1286.

27. Se YB, Chun HJ, Yi HJ, Kim DW, Ko Y, Oh SJ. Incidence and risk factors of infection caused by vancomycin-resistant enterococcus colonization in neurosurgical intensive care unit patients. J Korean Neurosurg Soc 2009; 46: 123-129. 